\title{
PENGARUH LATIHAN DRIBBLING RINTANGAN JARAK BERUBAH-UBAH DAN LATIHAN DRIBBLING RINTANGAN JARAK TETAP TERHADAP KEMAMPUAN DRIBBLING SEPAK BOLA PADA SISWA EKSTRAKURIKULER SMP NEGERI 15 SAMARINDA
}

\author{
Muhammad Aidil Arpat, Hendry Ismawan, S.Pd, M.Pd., Dr. Ruslan, M.Pd., \\ Pendidikan Jasmani Kesehatan dan Rekreasi \\ Muhammadaidilarpat@gmail.com
}

\begin{abstract}
ABSTRAK
Tujuan penelitian ini untuk meningkatkan kemampuan dribbling sepak bola pada siswa Ekstrakurikuler SMP Negeri 15 Samarinda dengan melakukan latihan dribbling rintangan jarak berubah-ubah dan latihan dribbling rintangan jarak tetap.

Jenis penelitian ini adalah eksperimen lapangan dengan melibatkan dua variabel bebas yaitu latihan dribbling rintangan jarak berubah-ubah dan latihan dribbling rintangan jarak tetap dan satu variabel terikat yaitu kemampuan dribbling sepakbola.

Populasi dalam penelitian ini adalah keseluruhan siswa ekstrakurikuler Ekstrakurikuler SMP Negeri 15 Samarinda. Pengambilan sampel menggunakan sistem random sampling, terbagi ke dalam 2 kelompok yaitu kelompok A dengan latihan dribbling rintangan jarak berubah-ubah dan kelompok B dengan latihan dribbling rintangan jarak tetap. Jumlah keseluruhan sampel sebanyak 20 orang. Teknik análisis data yang digunakan adalah statistik deskriptif dan statistik inferensial dengan menggunakan teknik uji t-test.

Berdasarkan análisis data diperoleh hasil: (1) Ada pengaruh latihan dribbling rintangan jarak berubah-ubah Terhadap Kemampuan dribbling sepak bola Pada Siswa Ekstrakurikuler SMP Negeri 15 Samarinda, terbukti nilai $\mathrm{t}$ hitung $=9,708 \geq \mathrm{t}$ tabel $=2,306$ berarti $\mathrm{H}_{1}$ diterima dan $\mathrm{H}_{\mathrm{o}}$ ditolak. (2) Ada pengaruh latihan dribbling rintangan jarak tetap Terhadap Kemampuan dribbling sepak bola pada siswa Ekstrakurikuler SMP Negeri 15 Samarinda, terbukti nilai $\mathrm{t}$ hitung $=14,307 \geq \mathrm{t}$ tabel $=2,306$ berarti $\mathrm{H}_{1}$ diterima. (3) Tidak ada perbedaan pengaruh latihan dribbling rintangan jarak berubah-ubah dan latihan dribbling rintangan jarak tetap Terhadap Kemampuan dribbling sepak bola pada siswa Ekstrakurikuler SMP Negeri 15 Samarinda, terbukti nilai $\mathrm{t}$ hitung $=0,438<\mathrm{t}$ tabel $=2,110$ berarti $\mathrm{H}_{\mathrm{o}}$ diterima dan $\mathrm{H}_{1}$ ditolak.
\end{abstract}


Kata kunci: dribbling rintangan jarak berubah-ubah, dribbling rintangan jarak tetap, kemampuan dribbling sepakbola.

\section{Pendahuluan}

a. Latar Belakang Penelitian

Pada jaman yang serba modern ini dimana manusia tidak dapat dipisahkan dari olahraga, baik dari segi olahraga prestasi, pendidikan,rekreasi maupun sebagai kebutuhan untuk menjaga kondisi tubuh agar tetap sehat jasmani dan rohani. Olahraga mempunyai peranan yang penting dalam kehidupan manusia,melalui olahraga dapat dibentuk manusia yang sehat jasmani, rohani serta mempunyai kepribadian disiplin, kuat, tangguh dan juga sportifitas yang tinggi sehingga pada akhirnya akan terbentuk manusia yang berkualitas.

Olahraga merupakan suatu aktivitas gerak tubuh, bagian atas dan bagian bawah. Merupakan aktivitas karena memiliki tujuan pada akhirnya, yakni kualitas hidup yang meningkat, sehingga menjadikan tubuh menjadi sehat dan bugar. Aktivitas menyehatkan ini selain dijadikan aktivitas pengisi waktu luang, juga dapat dijadikan sebagai sarana untuk mengasah kemampuan diri dalam berolahraga atau wadah untuk menjadi atlet profesional atau olahraga prestasi.

Salah satu olahraga permainan yang saat ini populer dan terkenal di indonesia bahkan didunia adalah permaianan sepakbola .Olahraga tersebut sangat digemari oleh seluruh lapisan masyarakat, baik anak anak, remaja dan bahkan orang dewasa. Olahraga ini bisa dikatakan sebagai olahraga rekreasi maupun prestasi bahkan olahraga ini selalu ada pada satuan kurikulum di sekolah.

Setelah peneliti melakukan observasi di sekolah SMP Negeri 15 Samarinda. Ditemui bahwa terdapat beberapa siswa dalam permainan sepakbola memiliki kemampuan yang kurang dalam hal kemampuan menggiring bola dan masih belum sepenuhnya menguasai teknik-teknik yang harus dilakukan, seperti perkenaan bola saat melakukan dribbling dalam permainan sepakbola belum benar dan pada saat siswa melakukan gerakan dribbling siswa kurang memainkan feeling sehingga bola yang di giring tidak dapat dikendalikan oleh siswa. Ini menandakan bahwa ada faktor yang mempengaruhi terhadap kemampuan tersebut. Penyebab yang paling dominan berdasarkan pengamatan adalah kurangnya kemampuan siswa dalam melakukan dribbling adalah dari siswa itu sendiri dimana rata-rata dari siswa peserta ekstrakurikuler sepakbola baru mengenal lebih dalam mengenai permainan sepakbola 
itu sendiri sebabnya pada tingkat sekolah sebelumnya kebanyakan dari siswa belum pernah bergabung dalam ekstrakurikuler atau pun sekolah sepakbola, di samping itu juga salah satu penyebab kurangnya keterampilan siswa dalam melakukan teknik dasar dribbling sepakbola adalah jarang melakukan latihan. Oleh karena itu untuk mengatasi masalah penyebab kurangnya kemampuan dribbling pada siswa perlu diadakannya atau dilakukannya latihan yang mengarahkan kepada peningkatan kemampuan dalam melakukan dribbling sepakbola.

Upaya peningkatkan kemampuan dribbling sepak bola dapat dilakukan dengan latihan secara sistematis dan kontinu. Untuk mencapai hasil latihan yang optimal dibutuhkan bentuk latihan yang baik dan tepat. Bentuk latihan merupakan suatu cara yang bertujuan untuk meningkatkan keterampilan bagi pemain yang dilatih. Tuntutan terhadap bentuk latihan yang efektif dan efisien didorong oleh kenyataan-kenyataan atau gejala-gejala yang timbul dalam pelatihan. Untuk meningkatkan ketepatan dan keterampilan pemain dalam melakukan teknik dribbling dibutuhkan bentuk latihan yang sesuai. Disini peneliti akan memberikan bentuk latihan dribbling rintangan jarak berubah-ubah dan dribbling rintangan jarak tetap dalam meningkatkan kemampuan dribbling sepak bola pada siswa SMP Negeri 15 samarinda. Untuk kedua bentuk latihan ini bisa saja digunakan di sekolah lain. Namun pada kali ini, SMP Negeri 15 Samarinda merupakan sampel yang digunakan peneliti untuk melakukan penelitian ini.

b. Rumusan Masalah

Rumusan masalah dalam penelitian ini adalah :

1) Apakah ada pengaruh latihan dribbling rintangan jarak berubah-ubah terhadap kemampuan dribbling sepak bola pada siswa Ekstrakurikuler SMP Negeri 15 Samarinda?

2) Apakah ada pengaruh latihan menggunakan gawang terhadap kemampuan dribbling sepak bola pada siswa Ekstrakurikuler SMP Negeri 15 Samarinda?

3) Apakah ada perbedaan pengaruh antara latihan dribbling rintangan jarak berubahubah dan latihan menggunakan gawang terhadap kemampuan dribbling sepak bola pada siswa Ekstrakurikuler SMP Negeri 15 Samarinda?

c. Tujuan Penelitian

Tujuan pelaksanaan penelitian ini adalah : 
1) Untuk mengetahui pengaruh latihan dribbling rintangan jarak berubah-ubah terhadap kemampuan dribbling sepak bola pada siswa Ekstrakurikuler SMP Negeri 15 Samarinda.

2) Untuk mengetahui pengaruh latihan dribbling rintangan jarak tetap terhadap kemampuan dribbling sepak bola pada siswa Ekstrakurikuler SMP Negeri 15 Samarinda.

3) Untuk mengetahui perbedaan pengaruh latihan dribbling rintangan jarak berubahubah dan latihan menggunakan gawang terhadap kemampuan dribbling sepak bola pada siswa Ekstrakurikuler SMP Negeri 15 Samarinda.

d. Manfaat Penelitian

Setiap penelitain diharapkan dapat bermanfaat bagi peneliti maupun pihak lain. Oleh karena itu penelitian diharapkan dapat berguna:

1) Memberikan informasi pada pembaca bahwa hasil lopat jauh gaya jongkok dapat dilatih dengan berbagai latihan, antara lain dengan latihan dribbling rintangan jarak berubah-ubah dan latihan dribbling rintangan jarak tetap.

2) Bagi siswa dengan penerapan latihan dribbling rintangan jarak berubah-ubah dan latihan dribbling rintangan jarak tetap akan meningkatkan daya ledak otot tungkai dan kekuatan otot tungkai serta dapat meningkatkan kemampuan dribbling sepak bola.

3) Untuk tambahan pengetahuan bagi guru pendidikan jasmani olahraga kesehatan mengenai bentuk latihan yang dapat diterapkan rangka meningkatkan kemampuan lompat jauh yaitu dengan latihan dribbling rintangan jarak berubah-ubah dan latihan menggunakan gawang. Dan sebagi acuan untuk meningkatkan kemampuan dribbling sepak bola pada siswa Ekstrakurikuler SMP Negeri 15 Samarinda.

4) Untuk sekolah dalam hal meningkatkan hasil lompat jauh, maka perlu didukung oleh sarana dan prasarana yang memadai.

5) Bagi peneliti sendiri sebagai bahan masukan dalam upaya meningkatkan kemampuan dribbling sepak bola.

\section{Kajian Pustaka dan Pengembangan Hipotesis}

a. Sepak Bola

Sepak bola adalah olahraga paling fenomenal dimuka bumi ini, tidak ada olahraga lain yang melebihi olahraga sepak bola dalam hal apapun. Tapi kebanyakan 
dari kita tidak tahu tentang sejarah sepak bola itu sendiri. Sepak bola adalah permaian bola yang dimainkan oleh dua tima dengan masing-masing beranggotakan sebelas orang. Olahraga ini sangat terkenal dan dimainkan di 200 negara dengan berbagai kejuaraan sepak bola yang diselengarakan oleh FIFA. Permainan sepak bola bertujuan untuk mencetak gol sebanyak-banyaknya dengan menggunakan bola kulit berukuran 27-28 inci. Lapangan yang digunakan dalam permaianan ini memiliki lebar 50-100 yard dan panjang 100-300 yard. Gawang tempat mencetak gol terletak di bagian ujung lapangan dengan dibatasi jarring berukuran tinggi 8 kaki dan lebar 24 kaki (AlHadiqie, 2013: 9).

\section{b. Teknik Dasar Permainan Sepakbola}

Menjadi pemain sepak bola perlu melakukan beberapa latihan teknik dasar dengan baik dan benar, serta ketekunan dalam berlatih, seperti teknik menendang, mengontrol dan menghentikan bola, menyundul, dan menggiring bola, serta teknik lainnya (Rahmani, 2014: 100).

Rahmani (2014: 100-101) ada empat teknik dasar didalam sepak bola yang perlu dikuasai yaitu :

1. Menendang bola

Menendang bola bertujuan untuk melakukan passing bola kepada teman satu tim yang kemudian dilanjutkan dengan berusaha memasukan bola ke dalam gawang. Teknik menendang juga terdiri dari tiga cara, yaitu menendang dengan menggunakan kaki bagian dalam, menendang dengan kaki bagian sebelah luar, dan menendang dengan menggunakan punggung kaki.

2. Mengontrol bola

Teknik ini merupakan teknik yang tidak kalah penting dari teknik dasar sepak bola lainnya. Karna dengan melatih teknik mengontrol bola, pemain dapat mengatur tempo permainan. Melakukan control bola yang baik dapat memudahkan memasukkan bola kedalam gawang dan mencetak kemenangan. Sementara pada saat akan menghentikan bola dapat dilakukan dengan menggunakan dada, paha, dan punggung kaki.

3. Menyundul bola

Teknik ini biasanya digunakan pemain pada saat memberikan operan tendangan sudut dan bertujuan untuk memasukkan bola kedalam gawang atau untuk menghindarkan gawang dari kemasikan bola yang di oper lawan.

4. Menggiring bola 
Teknik ini harus dilakukan dengan baik dan tenang. Menggiring bola sama seperti melakukan tendangan pendek, namun bola berada dekat kaki. Biasanya, teknik ini dilakukan untuk mendekati sasaran atau target dengan melewati beberapa lawan yang siap menghadang.

\section{c. Teknik Dasar Dribbling}

Teknik menggiring bola diartikan dengan gerakan lari menggunakan bagian kaki mendorong bola agar bergulir terus-menerus di atas tanah.Menurut Robert Koger (2007;51) menggiring bola (dribbling) adalah metode menggerakan bola dari satu titik ke titik lain di lapangan dengan menggunakan kaki. Adapun teknik menggiring bola terdiri dari menggiring bola dengan kura-kura kaki bagian dalam, kura-kura kaki penuh, kura-kura kaki bagian luar.

d. Latihan dribbling rintangan jarak berubah-ubah

Latihan ini merupakan gabungan dari dua latihan menggiring bola yang dikemukakan oleh koger dimana jarak antara rintangan satu dengan yang lain berbeda , hal ini bertujuan untuk memberikan latihan yang memiliki tingkat kesulitan lebih besar agar seorang pemain dapat meningkatkan kemampuan dan kecepatan menggiring bolanya. Seperti yang di utarakan Koger (2007:54) latihan menggiring bola melewati cones atau rintangan yang diletakkan secara acak atau berubah-ubah dapat meningkatkan kecepatan lari dan kontrol bola, selain itu juga dapat meningkatkan kemampuan mengubah arah dan mengubah.

e. Latihan dribbling rintangan jarak tetap

Latihan ini merupakan gabungan dari dua latihan menggiring bola yang dikemukakan oleh koger dimana jarak antara rintangan satu dengan yang lain berbeda , hal ini bertujuan untuk memberikan latihan yang memiliki tingkat kesulitan lebih besar agar seorang pemain dapat meningkatkan kemampuan dan kecepatan menggiring bolanya. Seperti yang di utarakan Koger (2007:54) latihan menggiring bola melewati cones atau rintangan yang diletakkan secara acak atau berubah-ubah dapat meningkatkan kecepatan lari dan kontrol bola, selain itu juga dapat meningkatkan kemampuan mengubah arah dan mengubah.

f. Hipotesis

Hipotesis yang dikemukakan dalam penelitian ini adalah sebagai berikut: 
1) Ada pengaruh latihan dribbling rintangan jarak berubah-ubah terhadap kemampuan dribbling sepak bola pada siswa Ekstrakurikuler SMP Negeri 15 Samarinda.

2) Ada pengaruh latihan dribbling rintangan jarak tetap terhadap kemampuan dribbling sepak bola pada siswa Ekstrakurikuler SMP Negeri 15 Samarinda.

3) Ada perbedaan pengaruh antara latihan dribbling rintangan jarak berubah-ubah dan latihan dribbling rintangan jarak tetap terhadap kemampuan dribbling sepak bola pada siswa Ekstrakurikuler SMP Negeri 15 Samarinda.

\section{Metode Penelitian}

a. Teknik pengumpulan data

Menurut Suharsimi Arikunto (2013 : 174), populasi adalah keseluruhan subjek penelitian. Sugiyono (2016: 117) menyatakan populasi adalah wilayah generalisasi yang terdiri atas objek atau subjek yang mempunyai kualitas dan karakteristik tertentu yang ditetapkan oleh peneliti untuk dipelajari dan kemudian ditarik kesimpulannya. Dalam penelitian ini yang menjadi populasi adalah semua siswa ekstrakurikuler sepak bola SMP Negeri 15 Samarinda dengan jumlah 27 orang.

b. Model penelitian

Penelitian ini mengunakan jenis penelitian eksperimen lapangan, dalam artian mengadakan kegiatan percobaan untuk melihat suatu hasil yang akan menegakkan kasual antara variabel yang diteliti, yaitu pengaruh latihan dribbling rintangan jarak berubah-ubah dan latihan dribbling rintangan jarak tetap terhadap kemampuan dribbling sepak bola pada siswa Ekstrakurikuler SMP Negeri 15 Samarinda.

Karena penelitian ini adalah penelitian eksperimen lapangan, maka rancangan penelitian yang dipergunakan adalah "Randomized Pretest-posttest Design". Rancangan penelitian ini dapat di gambarkan sebagai berikut:

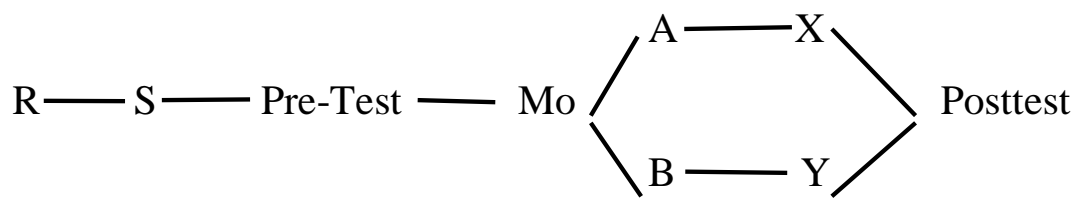

Gambar 2. Rancangan desain penelitian

Sumber: (Sugiono, 2013)

c. Devinisi Operasional

1) Latihan dribbling rintangan jarak berubah-ubah 
Latihan dribbling rintangan berubah ubah adalah menggiring bola dengan melewati-kun kun yang telah disusun dalam sebuah lingkaran yang jaraknya berubah-ubah dan dilewati dengan cara berurutan dan berakhir pada garis finish. Apabila latihan ini terus dilakukan dapat bermanfaat untuk meningkatkan lari dan kontrol bola juga dapat meningkatkan kemampuan mengubah arah bola dan mengubah kecepatan berlari saat pemain melakukan dribbling permainan sepak bola.

2) Latihan dribbling rintangan jarak tetap

Latihan dribbling rintangan jarak tetap adalah menggiring bola dengan melewati kun kun yang telah disusun dalam sebuah lingkaran yang jaraknya tetap dan dilewati berurutan sampai ke garis finish. Apabila latihan ini terus dilakukan dapat bermanfaat untuk meningkatkan lari dan kontrol bola jugaKemampuan dribbling sepak bola

\section{f. Metode Analisi Data}

Analisis data merupakan hal yang sangat penting, karena dengan analisis data penulis dapat mengabil suatu kesimpulan, mengenai diterimanya atau ditolaknya hipotesis yang telah diajukan. Data tentang pengaruh latihan dribbling rintangan jarak berubah-ubah dan latihan dribbling rintangan jarak tetap, kemampuan siswa melakukan lompat jauh gaya jongkok akan penulis analisis dengan mengunakan alat uji analisis berupa t-tes dengan rumus:

1) Statistik deskriftif, memberikan gambara umum hasil rata-rata standar deviasi variabel dari kedua kelompok.

2) Statistik inferensial, menguji hipotesis penelitian-penelitian dengan menggunakan uji-t pada taraf signifikan 95\%. Uji-t untuk menghitung perbedaan mean test awal dan test akhir untuk kedua kelompok yang berbeda.

\section{Hasil dan Pembahasan}

a. Hasil Penelitian

Untuk mengetahui keeratan pengaruh latihan dribbling rintangan jarak berubah-ubah dengan menggunakan program statistik SPSS 24.0. Rangkuman hasil analisis data dapat di lihat pada tabel 1 di bawah ini.

Tabel 1. Paired samples test

\begin{tabular}{|l|l|l|l|l|l|}
\hline Variabel & Mean & SD & t-hitung & $\begin{array}{c}\text { t-tabel } \\
(0.05: 8)\end{array}$ & Sig \\
\hline
\end{tabular}




\begin{tabular}{|l|l|l|l|l|l|}
\hline A1 - A2 & 2.375 & 0.77361 & 9.708 & 2.306 & 0.000 \\
\hline
\end{tabular}

Dari hasil pengujian hipotesis komparatif rata-rata dua sampel pada tabel 1 di atas diperoleh rata-rata sebelum dan sesudah diberi latihan dribbling rintangan jarak berubah-ubah $=2.375$ dengan standart deviasi $=0,77361$. $\mathrm{t}$ hitung $=9.708$ dengan derajat kebebasan 8 pada taraf kesalahan 5\%. Pada pengujian dua pihak dengan signifikansi sebesar 0,000 .

Kriteria pengujian menggunakan uji dua pihak yaitu, jika $t_{h}<t_{t(\alpha=0,05)}$ maka $H_{o}$ diterima dan $\mathrm{H}_{1}$ ditolak dan jika $\mathrm{t}_{\mathrm{h}} \geq \mathrm{t}_{\mathrm{t}(\alpha=0,05)}$ maka $\mathrm{H}_{1}$ diterima dan $\mathrm{H}_{\mathrm{o}}$ ditolak (atau signifikansi dibawah atau sama dengan 0,05 maka $\mathrm{H}_{1}$ diterima dan $\mathrm{H}_{\mathrm{o}}$ ditolak). Oleh karena nilai $\mathrm{t}$ hitung $=9.708 \geq \mathrm{t}$ tabel $=2,306$ berarti $\mathrm{H}_{1}$ diterima dan $\mathrm{H}_{\mathrm{o}}$ ditolak atau $0,000 \leq 0,05$ berarti $\mathrm{H}_{\mathrm{o}}$ ditolak dan $\mathrm{H}_{1}$ diterima, berarti ada pengaruh latihan mengguakan boks secara signifikan terhadap kemampuan dribbling sepak bola pada siswa Ekstrakurikuler SMP Negeri 15 Samarinda.

Untuk mengetahui keeratan pengaruh latihan menggunakan gawang dianalisa dengan menggunakan program statistik SPSS 24.0. Rangkuman hasil analisis data dapat di lihat pada tabel 2 di bawah ini:

Tabel 2. Paired samples test

\begin{tabular}{|c|c|c|c|c|c|}
\hline Variabel & Mean & SD & t-hitung & $\begin{array}{c}\text { t-tabel } \\
(0.05: 8)\end{array}$ & Sig \\
\hline B1 - B2 & 2.723 & 0,60187 & 14.307 & 2,306 & 0.000 \\
\hline
\end{tabular}

Dari hasil pengujian hipotesis komparatif rata-rata dua sampel pada tabel 8 di atas diperoleh rata-rata sebelum dan sesudah diberi latihan rintangan jarak tetap $=$ 2.723 dengan standart deviasi $=0,60187 . \mathrm{t}$ hitung $=14.307$ dengan derajat kebebasan 8 pada taraf kesalahan 5\%. Pada pengujian dua pihak dengan signifikansi sebesar 0,000 .

Kriteria pengujian menggunakan uji dua pihak yaitu, jika $t_{h}<t_{t(\alpha=0,05)}$ maka $H_{o}$ diterima dan $\mathrm{H}_{1}$ ditolak dan jika $\mathrm{t}_{\mathrm{h}} \geq \mathrm{t}_{\mathrm{t}(\alpha=0,05)}$ maka $\mathrm{H}_{1}$ diterima dan $\mathrm{H}_{\mathrm{o}}$ ditolak. Oleh karena nilai t hitung $=14.307 \geq \mathrm{t}$ tabel $=2,306$ berarti $\mathrm{H}_{1}$ diterima dan $\mathrm{H}_{\mathrm{o}}$ ditolak atau $0,000 \leq 0,05$ berarti $\mathrm{H}_{\mathrm{o}}$ ditolak dan $\mathrm{H}_{1}$ diterima, berarti ada pengaruh latihan menggunakan gawang secara signifikan terhadap kemampuan dribbling sepak bola pada siswa Ekstrakurikuler SMP Negeri 15 Samarinda. 
Untuk mengetahui keeratan perbedaan pengaruh latihan dribbling rintangan jarak berubah-ubah dan latihan dribbling rintangan jarak tetap di analisa dengan menggunakan program statistik SPSS 24.0

dapat di lihat pada tabel 3 di bawah ini:

Tabel 3. Independent Sample Test.

\begin{tabular}{|c|c|c|c|c|c|c|}
\hline kelompok & $\begin{array}{c}\text { Beda } \\
\text { mean }\end{array}$ & $\mathrm{F}$ & Sig. & $\begin{array}{c}\mathrm{t}- \\
\text { hitung }\end{array}$ & $\begin{array}{c}\mathrm{t} \text {-tabel } \\
(0.05: 17)\end{array}$ & $\begin{array}{c}\text { Sig. } \\
2 \text { tailed }\end{array}$ \\
\hline $\begin{array}{c}\text { Latihan A } \\
\text { latihan B }\end{array}$ & 0.437 & 0.336 & 0.569 & 0.438 & 2.110 & 0.667 \\
\hline
\end{tabular}

Kriteria pengujian menggunakan uji dua pihak yaitu, jika $t_{h}<t_{t(\alpha=0,05)}$ maka $H_{o}$ diterima dan $\mathrm{H}_{1}$ ditolak dan jika $\mathrm{t}_{\mathrm{h}} \geq \mathrm{t}_{\mathrm{t}(\alpha=0,05)}$ maka $\mathrm{H}_{1}$ diterima dan $\mathrm{H}_{\mathrm{o}}$ ditolak (atau signifikansi di bawah atau sama dengan 0,05 maka $\mathrm{H}_{1}$ diterima dan $\mathrm{H}_{\mathrm{o}}$ ditolak). Oleh karena nilai t hitung $=0,438<\mathrm{t}$ tabel $=2,110$ berarti $\mathrm{H}_{\mathrm{o}}$ diterima dan $\mathrm{H}_{1}$ ditolak atau 0,667 > 0,05 yang berarti $\mathrm{H}_{\mathrm{o}}$ diterima dan $\mathrm{H}_{1}$ ditolak.

Kesimpulannya: tidak terdapat perbedaan signifikan antara latihan dribbling rintangan jarak berubah-ubah dan latihan dribbling rintangan jarak tetap secara signifikan terhadap kemampuan dribbling sepak bola pada siswa Ekstrakurikuler SMP Negeri 15 Samarinda.

b. Pembahasan

Sesuai hasil uji-t data tes awal dan data tes akhir kemampuan dribbling sepak bola pada siswa Ekstrakurikuler SMP Negeri 15 Samarinda pada kelompok yang diberi metode latihan dribbling rintangan jarak berubah-ubah (A) di peroleh hasil dengan nilai $\mathrm{t}$ hitung $=9.708 \geq \mathrm{t}$ tabel $=2,306$ berarti $\mathrm{H}_{1}$ diterima dan $\mathrm{H}_{\mathrm{o}}$ ditolak atau $0,000 \leq 0,05$ berarti $\mathrm{H}_{\mathrm{o}}$ ditolak dan $\mathrm{H}_{1}$ diterima, berarti ada pengaruh latihan dribbling rintangan jarak berubah-ubah secara signifikan terhadap kemampuan dribbling sepak bola pada siswa Ekstrakurikuler SMP Negeri 15 Samarinda membuktikan bahwa hipotesis pertama yang diajukan diterima. Sehingga dapat dikemukakan bahwa dengan memberikan latihan dribbling rintangan jarak berubah-ubah secara terprogram maka akan dapat meningkatkan kemampuan dribbling sepak bola. Dapat dijelaskan bahwa dalam melakukan atau melaksanakan latihan dribbling rintangan jarak berubah-ubah ini memiliki manfaat yang dapat mendukung dalam meningkatkan kemampuan 
dribbling sepak bola sebab latihan ini mengarah pada peningkatan kecepatan dan kelincahan pada siswa.

Pengaruh latihan dribbling rintangan jarak tetap terhadap kemamuan dribbling sepak bola pada siswa Ekstrakurikuler SMP Negeri 15 Samarinda. Sesuai hasil uji-t data tes awal dan data tes akhir kemampuan dribbling sepak bola pada siswa Ekstrakurikuler SMP Negeri 15 Samarinda pada kelompok yang diberi latihan dribbling rintangan jarak tetap (B) diperoleh nilai $\mathrm{t}$ hitung $=14,307 \geq \mathrm{t}$ tabel $=2,306$ berarti $\mathrm{H}_{1}$ diterima dan $\mathrm{H}_{\mathrm{o}}$ ditolak atau $0,000 \leq 0,05$ berarti $\mathrm{H}_{\mathrm{o}}$ ditolak dan $\mathrm{H}_{1}$ diterima, berarti ada pengaruh latihan dribbling rintangan jarak tetap secara signifikan terhadap kemampuan dribbling sepak bola pada siswa Ekstrakurikuler SMP Negeri 15 Samarinda. Dapat dikemukakan bahwa dengan memberikan latihan dribbling rintangan jarak tetap secara terprogram selama 24 kali pertemuan dengan perincian tiga kali perminggu, maka akan dapat meningkatkan kemampuan dribbling sepak bola, hal ini dikarenakan meningkatnya kecepatan dan kelincahan pada siswa ketika melakukan teknik dasar dribbling.

kemampuan dribbling sepak bola yang diberi latihan dribbling rintangan jarak berubah-ubah dan latihan dribbling rintangan jarak tetap diperoleh $\mathrm{t}$ hitung $=0,438$, derajat kebebasan 17 , perbedaan rata-rata $=0,437$, dengan standar kesalahan perbedaan $=0,998$ dan signifikansi $=0,569$. Oleh karena nilai $\mathrm{t}$ hitung $=0,185<\mathrm{t}$ tabel $=2,100$ berarti $\mathrm{H}_{\mathrm{o}}$ diterima dan $\mathrm{H}_{1}$ ditolak atau 0,667>0,05 yang berarti $\mathrm{H}_{\mathrm{o}}$ diterima dan $\mathrm{H}_{1}$ ditolak.

sehingga tidak terdapat perbedaan pengaruh yang signifikan antara latihan dribbling rintangan jarak berubah-ubah dan latihan dribbling rintangan jarak tetap terhadap kemampuan dribbling sepak bola pada siswa Ekstrakurikuler SMP Negeri 15 Samarinda.

\section{Kesimpulan dan Keterbatasan}

a. Kesimpulan

Berdasarkan analisis data dan pembahasannya maka hasil penelitian ini dapat disimpulkan sebagai berikut:

1) Latihan dribbling rintangan jarak berubah-ubah berpengaruh terhadap kemampuan dribbling sepak bola pada siswa Ekstrakurikuler SMP Negeri 15 Samarinda. 
2) Latihan dribbling rintangan jarak tetap berpengaruh terhadap kemampuan dribbling sepak bola pada siswa Ekstrakurikuler SMP Negeri 15 Samarinda.

3) Tidak ada pengaruh yang signifikan antara latihan dribbling rintangan jarak berubah-ubah dan latihan dribbling rintangan jarak tetap terhadap kemampuan dribbling sepak bola pada siswa Ekstrakurikuler SMP Negeri 15 Samarinda.

b. Saran

Dengan hasil kesimpulan yang diperoleh, maka saran-saran yang diberikan dalam penelitian ini adalah sebagai berikut:

1) Bagi para pembina, guru maupun pelatih olahraga khususnya pada cabang olahraga sepak bola disarankan untuk latihan dribbling rintangan jarak berubah-ubah dan latihan dribbling rintangan jarak tetap dalam melatih kemampuan dribbling sehingga dapat memperoleh hasil dribbling yang baik.

2) Supaya pembinaan olahraga sepak bola khususnya di tim sepak bola SMP Negeri 15 Samarinda dapat mencapai hasil yang maksimal maka perlu disarankan kepada pelatih serta sekolah untuk menyiapkan sarana dan prasarana pendukung yang memadai terutama yang mendukung kegiatan siswa dalam mengeksplorasikan keterampilannya dalam suatu season latihan.

3) Bagi para siswa, direkomendasikan perlunya mengetahui dan mengembangkan unsur latihan dribbling rintangan jarak berubah-ubah dan latihan dribbling rintangan jarak tetap untuk meningkatkan kemampuan dribbling serta memperhatikan unsur antropometrik tubuh yang tidak teramati dalam penelitian ini.

4) Bagi para mahasiswa yang berminat melakukan penelitian lebih lanjut, disarankan agar melibatkan variabel-variabel lain yang relevan dengan penelitian ini disertai dengan populasi dan sampel yang lebih luas.

\section{Daftar Pustaka}

Arikunto, Suharsimi. 2013. Prosedur Penelitian Suatu Pendekatan Praktik. Jakarta: PT. Rineka Cipta.

Koger, Robert. 2007. Latihan dasar andal sepak bola remaja. Klanten: Macanan jaya kencana.

Rahmani,Mikanda. 2014. Buku Super Lengkap Olahraga. Jakarta: Dunia Cerdas. 
Sugiono. 2016. Metode Penelitian Pendidikan Pendekatan Kuantitatig, Kualitatif, dan R\&D. Bandung: Alfabeta PT Remaja Rosda Karya.

Zidane Muhdhor Al-Hadiqie. 2013. Menjadi pemain Sepak Bola Profesional. Kata Pena. 